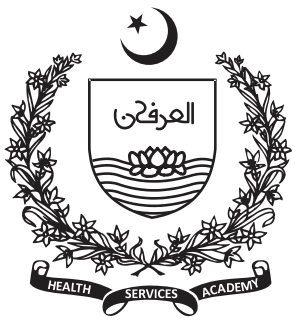

\title{
Affiliation of Postpartum Depression with Mode of Delivery; A Disregarded Domain
}

\author{
Aisha khan jadoon ${ }^{1}$, Arzu jadoon ${ }^{2}$, Sarosh khan jadoon ${ }^{3}$, Shahina Ishtiaq ${ }^{4}$
}

\section{Abstract}

${ }^{1}$ Resident, Ob/Gynae

Department, Aga Khan University Hospital,

Karachi, Pakistan

2Resident, Medicine

Department, Ziauddin

University Hospital,

Karachi, Pakistan

${ }^{3}$ Resident Medical Officer, Surgery Department,

Ziauddin University

Hospital, Karachi, Pakistan

${ }^{4}$ Associate Professor, Ob/gynae Department, Ziauddin University Hospital, Karachi, Pakistan

Corresponding Author: Aisha Khan Jadoon Email:

aishajadoon@hotmail.com
Background: Postpartum Depression is a serious issue that can lead to irreversible disasters if not timely recognized and diagnosed. There are various modes of delivery; which may contribute towards physical and mental trauma.

Methods: It was a prospective descriptive cross- sectional study carried out to evaluate the alliance of postnatal depression with different modes of delivery i.e. vaginal or lower segment caesarean section. The study was conducted at Ziauddin University Hospital. A sample size of 200 was taken. It was carried out from June 2019 to December 2019. A Performa was designed that questioned about different socio-demographic characteristics and risk factors for post-natal depression (PND). Edinburg Post-Natal Depression Scale (EPNDS) was used for authenticated identification of women with depression in purpeurium.

Results: Out of the total sample of 200 women, 100 were taken from the spontaneous vaginal delivery group and 100 from cesarean section group. Mean age was $21-34$ years. It was noticed that $60 \%$ women who underwent cesarean section became a victim of depression and $40 \%$ women who had a normal vaginal delivery were identified to have post natal depression.

Conclusion: The study identifies cesarean section to be one of the culprits of postnatal depression as compared to woman undergoing spontaneous vaginal delivery. There is an exponential rise in the frequency of performing unexplained cesarean sections that would also boost up the graphs of postnatal depression; hence there is a dire need to instruct women to follow up postnatal so that they can be evaluated for post partum depression.

Keywords: Postpartum depression; mode of delivery; maternal morbidity

\section{Introduction}

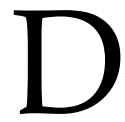
epression is a major cause of disability and a leading culprit in raising the global burden of disease. According to World Health Organization (WHO) depressive disorders stand at the $4^{\text {th }}$ position at the moment, but might ascend to $2^{\text {nd }}$ by
2020. ${ }^{1} 34$ percent of the population is suffering from depression in Pakistan (2). The period of pregnancy and puerperium is linked with many changes that might become the reason for psychiatric disorders most commonly depression, especially among women with genetic or psychosocial risk factors. Hence, mothers are very likely to develop mood disorders in 
the postpartum period(3). This can adversely influence mother-baby bonding, self harm or sometimes infanticide. It may lead to irreparable consequences if not addressed timely.

One can categorize Post-partum psychiatric disorders as postpartum blues, post partum psychosis and post partum depression (PPD), by weighing them over time frames. According to the Diagnostic and Statistical Manual for Mental Disorders (DSM-IV-TR) and the International Classification of Diseases (ICD$10)$, the period of postpartum depression can be defined as four to six weeks after birth. It can also initiate soon after childbirth or as a sequelae of antenatal depression. The National Institute for Health and Care Excellence (NICE) guidelines recommends PPD screening at 4-6 weeks after delivery; however it should be stated that the incidence of mood disorders is highest during the first 3 months postpartum, sometimes a year (3)."Baby blues" or postpartum blues occurring between 3 to 10 days post-delivery, has few negative symptoms and usually requires only reassurance. Its incidence is 300-750 per 1000 mothers globally(4). While, "Post-natal psychosis" has a global prevalence ranging from 0.89 to 2.6 per 1000 births which affects 1 in 500 women in the first week or so postpartum(5).

It is estimated that overall 10 to $15 \%$ women experience PPD in the western world(6). Researches on prevalence of PPD conclude developing countries face its greatest burden. In Asian countries the prevalence rate ranges from $3.5 \%$ to $63.3 \%$. Pakistan has the highest rate amongst Asian countries that is $28 \%-63 \%$ (7). Whereas, in Indian mothers it was found to be $22 \%$ (8). Iran showed the prevalence of PPD as $35.4 \%$ (9). According to a review study conducted in 2018, overall, the prevalence of PND ranged from $4.0 \%$ to $63.9 \%$, with Japan and America recording the lowest and highest rates of PND, respectively (10)

Caesarian section has been statistically proven to have increased by $60 \%$ and evidence suggests an association with psychiatric disorders (11). Many studies have shown that the actual CS rate in numerous countries is far higher than that recommended by the World Health Organization. The prevalence of caesarean deliveries among women in Pakistan rose from $7.3 \%$ in 2008 to $14 \%$ in 2013(12).The result of the World Health Organization global survey in a large cross-sectional study proved that severe maternal morbidity in planned cesarean delivery is higher than that in planned vaginal delivery (13).
There are many conflicting studies present, some showing correlation ${ }^{14-16}$ while others showing no correlation $(17,18,19)$ between mode of delivery and PPD.

Therefore, the purpose of this study is to assess the prevalence of PPD and examine the risk factors particularly frequency of PPD in women undergoing Normal Vaginal Delivery and Caesarian sections. This will help in early identification of women at risk, hence preventive measures and treatment strategies can be drafted accordingly in order to enhance the well-being of women.

\section{Methodology}

The study was conducted at Ziauddin University Hospital, Keamari campus that is a 100 bedded tertiary care facility. It caters to middle and lower socio-economic strata. Questionnaires were filled by researchers after informed consent from participants. It was a prospective cross sectional study. 200 patients were included in the study that fulfilled the inclusion criteria through non-probability sampling technique. It took six months; June 2019 to December 2019, to gather a sample of 200 patients. Adult age group that is above 14 years was included that was further divided into 3 sub-groups: <20 years, 21-34 years and $\geq 35$. Equal number of patients, under-going cesarean section and normal vaginal delivery were taken. Sample size for each group was 100. Patients were assessed 1-8 weeks post delivery. Patients with a history of psychiatric illnesses or depression or family history of depression were excluded out.

Questionnaire was filled 1-8 weeks post delivery by all authors. Privacy was maintained throughout the interview. Details of participant's demographics and detailed history such as age; parity; BMI (Body Mass Index); education; booking status; socioeconomic status; co-morbids; planned or unplanned pregnancy, addiction; gestational age at which baby was delivered; duration of labour; length of stay at the hospital; delivery complications; place of delivery were documented. Different modes of delivery were inculcated that include vaginal route: SVD (spontaneous vaginal delivery), Instrumental (vacuum vaginal delivery/VVD, forceps vaginal delivery/FVD), TOP (Termination of Pregnancy), D\&E (Dilatation and evacuation), MVA (Manual vacuum aspiration) as well as surgical route: ELLSCS (Elective lower section cesarean section) EMLSCS (Emergency lower section cesarean section). Baby's 
gender and outcome of pregnancy was also enquired. Previous history of psychiatric illness or depression and family history of depression were also recorded. Edinburgh Postnatal Depression Scale (EPDS) was used to assess depression among patients in this study. It comprises of 10 questions (symptoms) about how the patient feels for the past 7 days. Women who score above 10 are suffering from a depressive illness. Questions 1, 2, \& 4 (without an *) are scored $0,1,2$ or 3 with top box scored as 0 and the bottom box scored as 3. Questions 3, 5, 10(marked with an *) are reverse scored, with the top box scored as a 3 and the bottom box scored as 0. Maximum score is 30, Possible Depression: 10 or greater. It is important to notice item 10 (suicidal thoughts). For this study, all EPDS items were translated into Urdu language.

Data was analyzed by version 20 of SPSS. Chi square was applied and $\mathrm{p}$ value $<0.05$ was taken as significant. BMI was calculated using standard formula weight in $\mathrm{kg} /$ height in $\mathrm{m}^{2}$. Socio economic status was determined by income per capita. It was divided into three classes, lower class ( $<$ Rs 10000), middle (Rs10-90000) and higher $\geq$ Rs100, 000).

\section{Results}

200 women were included in the study. Of these 100 underwent Caesarian section and 100 were SVD. 46 had emergency lower section caesarian sections (EMLSCS) and 54 had elective (ELLSCS). 87 women went through SVD, 8 Instrumental, 5 D\&E/MVA/TOP. 135 women belonged to the age group 21-34years. 34 were more than or equal to 35 years old and 31 were $\leq 20$ years old.

The total rate of depression was $29 \%$ (58/200), which consisted of $60 \%$ and $40 \%$ in Caesarian section and SVD respectively. There was a significant relationship between mode of delivery and postpartum depression ( $P$ value 0.000$)$ as seen in figure 1.

No association was found between variables like age; parity; BMI; education; booking status; socioeconomic status; addiction; gestational age; length of stay; delivery complications; place of delivery with PPD, as shown in table 1.

There were 50 women that had some sort of comorbids but it was not significant with the development of PPD. Being an open ended question; co-morbids that were noted down included 12 cases of GDM out of which 6 developed PND, 7 anemia and 2 got PND, 2/5 Hypertensives developed PND, 3/4 Hepatitis B, 2/4 PIH, 3/3 PCOS cases got PND, 2 DM
2 and one each for $\mathrm{APH}, \mathrm{DM}$, goiter, eclampsia, Hepatitis C, ovarian cyst, PPH and preeclampsia. Table 1 and 2 demonstrate the socio-demographic factors in detail.

Total EPDS mean score was $5.97 \pm 6.17$. Refer to table 3 for EPDS means for various modes of delivery.

Table 1 SOCIO DEMOGRAPHIC FACTORS AND PPD

\begin{tabular}{|c|c|c|}
\hline FACTORS & $\begin{array}{l}\text { DEPRESSIO } \\
\mathrm{N}\end{array}$ & $\begin{array}{l}\text { P- } \\
\text { VALU } \\
\text { E }\end{array}$ \\
\hline $\begin{array}{l}\text { AGE } \\
\leq 20 \text { years } \\
21-34 \text { years } \\
>35\end{array}$ & $\begin{array}{l}10 / 31 \times 100= \\
32 \% \\
35 / 135 \times 100= \\
26 \% \\
13 / 34 \times 100= \\
38 \%\end{array}$ & 0.335 \\
\hline $\begin{array}{l}\text { PARITY } \\
\text { Primi } \\
\text { Multi } \\
\text { Grandmulti }\end{array}$ & $\begin{array}{l}30 / 105 \times 100= \\
29 \% \\
25 / 76 \times 100= \\
33 \% \\
3 / 19 \times 100= \\
16 \%\end{array}$ & 0.336 \\
\hline $\begin{array}{l}\text { BMI } \\
\text { Normal } \\
\text { Underweight } \\
\text { Overweight } \\
\text { Obese }\end{array}$ & $\begin{array}{l}21 / 82 \times 100= \\
26 \% \\
9 / 18 \times 100= \\
50 \% \\
22 / 82 \times 100= \\
27 \% \\
6 / 18 \times 100= \\
33 \%\end{array}$ & 0.198 \\
\hline $\begin{array}{l}\text { EDUCATION } \\
\text { None } \\
\text { Primary } \\
\text { Secondary } \\
\text { Higher }\end{array}$ & $\begin{array}{l}15 / 36 \times 100= \\
42 \% \\
34 / 129 \times 100= \\
26 \% \\
8 / 30 \times 100= \\
27 \% \\
1 / 5 \\
20 \%\end{array}$ & 0.318 \\
\hline $\begin{array}{l}\text { SOCIOECONOMICSTAT } \\
\text { US } \\
\text { Upper } \\
\text { Middle } \\
\text { Lower } \\
\end{array}$ & $\begin{array}{l}1 / 5 \times 100= \\
20 \% \\
45 / 159 \times 100=\end{array}$ & 0.830 \\
\hline
\end{tabular}


Original Article

\begin{tabular}{|l|l|l|}
\hline & $\begin{array}{l}28 \% \\
11 / 36 \times 100=\end{array}$ & \\
& $31 \%$ & \\
\hline BOOKING STATUS & & \\
Booked & $34 / 120 \times 100=$ & 0.460 \\
Un-booked & $28 \%$ & \\
& $24 / 80 \times 100=$ & \\
& $30 \%$ & \\
\hline
\end{tabular}

\begin{tabular}{|c|c|c|}
\hline $\begin{array}{l}\text { ELLSCS } \\
\text { EMLSCS } \\
\text { SVD } \\
\text { INSTRUMENTAL(VVD } \\
\text { /FVD) } \\
\text { D\&E/MVA/TOP }\end{array}$ & $\begin{array}{ll}12 / 54 & \times 100= \\
22 \% & \\
23 / 46 & \times 100= \\
50 \% & \\
16 / 87 & \times 100= \\
18 \% & \\
3 / 8 & \times 100= \\
38 \% & \\
4 / 5 & \times 100= \\
80 \% & \end{array}$ & 0.000 \\
\hline $\begin{array}{l}\text { BABY'S GENDER } \\
\text { MALE } \\
\text { FEMALE } \\
\text { UNDETERMINED }\end{array}$ & $\begin{array}{l}13 / 96 \times 100= \\
14 \% \\
44 / 102 \times 100= \\
43 \% \\
1 / 2 \times 100= \\
50 \%\end{array}$ & 0.000 \\
\hline $\begin{array}{ll}\text { DURATION } & \text { OF } \\
\text { LABOUR } & \\
\text { ADEQUATE } & \\
\text { PROLONGED } & \\
\text { NOT APPLICABLE } & \end{array}$ & $\begin{array}{l}20 / 94 \quad \times 100= \\
21 \% \\
14 / 22 \quad \times 100= \\
64 \% \\
24 / 84 \times 100= \\
29 \%\end{array}$ & 0.000 \\
\hline $\begin{array}{l}\text { DELIVERY OUTCOME } \\
\text { HEALTHY CHILD } \\
\text { MISCARRIAGE/RPOCS } \\
\text { FETAL/NEONATAL } \\
\text { DEATH } \\
\text { LOW APGAR SCORE }\end{array}$ & $\begin{array}{l}14 / 127 \times 100= \\
11 \% \\
8 / 9 \\
89 \% \\
9 / 12 \times 100= \\
75 \% \\
27 / 52 \times 100= \\
52 \%\end{array}$ & 0.000 \\
\hline $\begin{array}{l}\text { PREGNANCY STATUS } \\
\text { PLANNED } \\
\text { UN-PLANNED }\end{array}$ & $\begin{array}{l}21 / 156 \times 100= \\
13 \% \\
37 / 44 \times 100= \\
84 \%\end{array}$ & 0.000 \\
\hline
\end{tabular}

Table 2 FACTORS ASSOCIATED WITH PPD

\begin{tabular}{|c|c|c|}
\hline FACTORS & DEPRESSION & $\begin{array}{l}\text { P- } \\
\text { VALUE }\end{array}$ \\
\hline $\begin{array}{l}\text { ADDICTION } \\
\text { Betal nuts/leaf } \\
\text { Cigarretes/sheesha } \\
\text { Chewable tobacco } \\
\text { Drug addiction } \\
\text { None }\end{array}$ & $\begin{array}{l}18 / 59 \times 100= \\
31 \% \\
2 / 8 \times 100= \\
25 \% \\
5 / 17 \times 100= \\
29 \% \\
1 / 1 \times 100= \\
100 \% \\
32 / 115 \times 100= \\
28 \%\end{array}$ & 0.617 \\
\hline $\begin{array}{l}\text { GESTATIONAL AGE } \\
\text { Preterm } \\
\text { Term } \\
\text { Post term }\end{array}$ & $\begin{array}{ll}8 / 16 & \times 100= \\
50 \% & \\
49 / 180 & \times 100= \\
27 \% & \\
1 / 4 & \times 100= \\
25 \% & \end{array}$ & 0.155 \\
\hline $\begin{array}{l}\text { PLACE OF DELIVERY } \\
\text { Hospital } \\
\text { House } \\
\text { Local clinic }\end{array}$ & $\begin{array}{l}55 / 196 \quad \times 100= \\
28 \% \\
1 / 2 \times 100= \\
50 \% \\
2 / 2 \\
100 \%\end{array}$ & 0.067 \\
\hline $\begin{array}{l}\text { DELIVERY } \\
\text { COMPLICATIONS } \\
\text { No } \\
\text { Yes }\end{array}$ & $\begin{array}{l}4 / 15 \\
27 \% \\
54 / 185 \\
29 \%\end{array} \quad \times 100=$ & 0.549 \\
\hline $\begin{array}{l}\text { LENGTH OF STAY } \\
\text { Adequate } \\
\text { Prolonged }\end{array}$ & 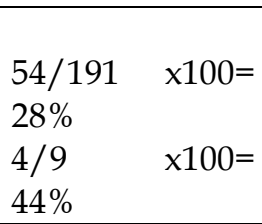 & 0.244 \\
\hline MODE OF DELIVERY & & \\
\hline
\end{tabular}

Table 3 EPDS MEAN SCORES

\begin{tabular}{|l|l|l|}
\hline $\begin{array}{l}\text { MODE OF } \\
\text { DELIVERY }\end{array}$ & $\begin{array}{l}\text { EPDS } \\
\text { SCORE } \\
\text { Mean }\end{array}$ & Std. Deviation \\
\hline ELLSCS & 4.4259 & 5.37851 \\
\hline EMLSCS & 8.6957 & 6.24987 \\
\hline SVD & 4.8851 & 5.40763 \\
\hline $\begin{array}{l}\text { INSTRUMENTA } \\
\text { L(VVD/FVD) }\end{array}$ & 6.7500 & 7.74135 \\
\hline
\end{tabular}

Pak J Public Health; Vol 10(1): March 2020 


\begin{tabular}{|l|l|l|}
\hline D\&E/MVA/TOP & 15.2000 & 9.36483 \\
\hline
\end{tabular}

Nevertheless, there were other factors that were statistically significant as shown in table 2. This included mode of delivery that was the objective of the study along with pregnancy status of the mother, baby's gender, duration of labour and outcome of pregnancy. 20 women out of 200 had thought of harming themselves. Mean EPDS score was 5.97 \pm 6.17 .

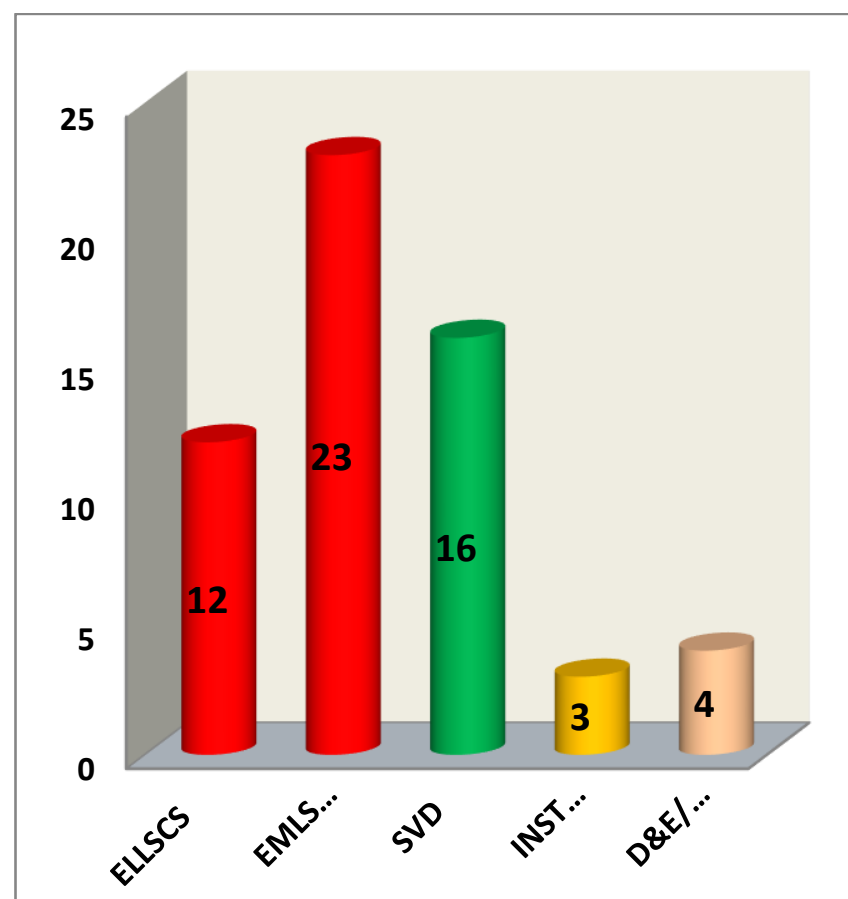

Figure 1 MODE OF DELIVERY AND DEVELOPMENT OF POST NATAL DEPRESSION

\section{Discussion}

Studies conducted in the past have described that women undergoing caesarean section are more prone to suffer post natal depression as compared to those that undergo a normal vaginal delivery; this is in accordance with the findings of the current study. Majority of the sample lied in the age range of 21-34 years, however the most depressed ones were found in age group of $>35$ years. Similarly the highest rate of depression was found in women having multigravidas, under weights, low education, un-booked pregnancies and socioeconomically lower class. Other strong factors that play a role in developing depression in such women seemed to be drug addiction, delivery complications, pre-term deliveries, home deliveries and prolonged length of stay at the hospital. However, all these factors were statistically insignificant and these findings were consistent with researches previously conducted. $(20,21)$

In the current study a significant relationship was found between post natal depression and pregnancy status; whether it was planned or unplanned. It clearly showed that un-planned pregnancy raised the chances of PND. Barton K concluded his study with exact results. (22)

Furthermore, the study revealed a disappointing association between PND and gender of the child born. Mothers were found to be more depressed on birth of a female child as compared to a male child. This was also addressed in the journal of Obstetrics and Gynaecology in 2007 (23). However, Sarah et al in her recent study discovered that male gender is more likely to give PND to their mothers. (24)

The current study also exerts the fact that prolonged labour and poor delivery outcome can leave deep imprints on the psychological well being of a mother. Many studies have emphasized on the importance of smooth delivery and its effects on PND. (25)

Stein et al and Ali et al carried out studies in 2012 and 2013 respectively and the findings confirmed that there was 6 times more risk of emotional development delay and impaired mother-infant interactions as well as disrupted emotional and cognitive development of the infant in depressed mothers as compared to non depressed mothers. $(26,27)$

In the present study 29 percent of the total sample was observed to be depressed postnatal. Three-fifth had undergone cesarean section whereas two-fifth had experienced normal vaginal deliveries. This was statistically significant. A pilot study conducted by Edwards DR et al also gave identical results (28).A review study that was carried out to explore the link between caesarean section and PND declared that out of 24 studies 5 studies had significant adverse association, 15 had no significant adverse association and 4 studies were having mixed results (19).

A pilot study conducted in Peshawar in 2015 also declared that postnatal depression is significantly more common in the females undergoing caesarian sections as opposed to the normal vaginal deliveries (29). Likewise, the results of a study carried out in Taiwan showed that the risk of acquiring PND was lower in mothers with a normal vaginal delivery or an instrumental vaginal delivery compared to mothers 
with an emergency caesarean section. ${ }^{15} \mathrm{~A}$ similar study conducted on Nigerian women stated that caesarean childbirth may predispose mothers to adverse psychological problems. (16)

Small sample size was the biggest limitation in this study. A larger sample size from major private and government sectors would be helpful in finding incidence of the problem. Researches should be conducted in Pakistan for exploring other factors that may gaslight the development of PND.

\section{Conclusion}

Postnatal Depression is highly significant in women who undergo caesarean section as compared to those who undergo a normal vaginal delivery. Hence preprocedure counseling and post-procedure mental evaluation with special care would be beneficial in decreasing the anxiety level of undergoing a surgical procedure. Further studies can be conducted to prove how a good counseling session before a caesarean section can eliminate mode of delivery from among the risk factors leading to PND.

\section{References}

1. van Dooren FE, Nefs G, Schram MT, Verhey FR, Denollet J, Pouwer F. .Depression and risk of mortality in people with diabetes mellitus: a systematic review and meta-analysis; journal.pone. epub 2013;8(3):e57058

2. World Health Organization. The world health report, mental health: new understanding, new hope. Geneva: WHO; 2001.

3. Farhat A et al. Prevalence of postpartum depression in NICU,Iranian Journal of Neonatology 2015; 6(3)

4. Stewart DE, Robertson E, Dennis CL, Grace SL, Wallington T. Postpartum depression: literature review of risk factors and interventions. Toronto: University Health Network Women's Health Program;2003,http://www.who.int/mental_health/pre vention/suicide/lit_review_postpartum_depression.pd f [cited 2017 May 16].

5. VanderKruik R, Barreix M, Chou D, Allen T, Say L, Cohen LS; Maternal Morbidity Working Group. The global prevalence of postpartum psychosis: a systematic review. BMC Psychiatry. $2017 \quad 07$ 28;17(1):272. http://dx.doi.org/10.1186/s12888-017-1427-7 pmid: 28754094

6. Reindolf Anokye,Prevalence of postpartum depression and interventions utilized for its management Ann Gen Psychiatry. 2018; 17: 18
7. Aliani R Epidemiology of Postpartum Depression in Pakistan: A Review of Literature National Journal of Health Sciences, 2017, 2, 24-30

8. Upadhyay RP, Postpartum depression in India: a systematic review and meta-analysis Bulletin of the World Health Organization 2017;95:706-717C. doi:http:/ /dx.doi.org/10.2471/BLT.17.192237

9. Jahanihashemi E et al,The Prevalence of Postpartum Depression and Its Association with Food Insecurity among Mothers Referring to Community Health Centers,Iranian J Psychiatry 2018, 13: 4

10. Arifin SRM, Review of the prevalence of postnatal depression across cultures, AIMS Public Health. 2018; 5(3): 260-295.

11. Torkan B, Parsay S, Lamieian M, Kazemnezhad A, Montazeri A (2008) Comparative analysis of life quality in mothers after cesarean section and normal vaginal delivery. Iranian Journal of Nursing and Midwifery Research 12: 1.

12. Aaisha Amjad, Factors associated with caesarean deliveries among child-bearing women in Pakistan: secondary analysis of data from the Demographic and Health Survey, BMC Pregnancy and ChildbirthBMC series - open, inclusive and trusted, 2018. 18:113

13. Souza JP, Gulmezoglu A, Lumbiganon P et al. Caesarean section without medical indications is associated with an increased risk of adverse short-term maternal outcomes: The 2004-2008 WHO Global Survey on Maternal and Perinatal Health. BMC Med 2010; 8: 71.

14. Xie RH, Lei J, Wang $S$, Xie H, Walker M, Wen SW. Cesarean section and postpartum depression in a cohort of Chinese women with a high cesarean delivery rate. $J$ Womens Health 2011; 20: 1881-1886

15. Yang SN, Shen LJ, Ping T,Wang YC, Chien CW. The delivery mode and seasonal variation are associated with the development of postpartum depression. J Affect Disord 2011; 132:158-164.

16. Ukpong DI, Owolabi AT. Postpartum emotional distress: A controlled study of Nigerian women after caesarean childbirth. J Obstet Gynaecol 2006; 26: 127-129.

17. Sword W, Landy CK, Thabane L, Watt S, Krueger P, et al. (2011) Is mode of delivery associated with postpartum depression at 6 weeks: a prospective cohort study. BJOG 118: 966-977.

18. Adams S, Eberhard-Gran M, Sandvik A, Eskild A. Mode of delivery and postpartum emotional distress: A cohort study of 55814 women. BJOG 2012; 119: 298-305.

19. Carter FA, Frampton CM, Mulder RT. Cesarean section and postpartum depression: A review of the evidence examining the link. Psychosom Med 2006; 68: 321-330.

20. Arbabi M, Taghizadeh Z, Hantoushzadeh S, Haghnazarian E (2016) Mode of Delivery and Postpartum Depression: A Cohort Study. J Women's Health Care 5: 303. doi:10.4172/2167-0420.1000303

21. Malik FR, Malik BB, Irfan M. Comparison of postnatal depression in women following normal vaginal delivery 
and caesarean section: A pilot study. J Postgrad Med Inst 2015; 29(1): 34-7

22. Barton $\mathrm{K}$ et al, Unplanned pregnancy and subsequent psychological distress in partnered women: a crosssectional study of the role of relationship quality and wider social support BMC Pregnancy Childbirth. 2017; 17: 44. . doi: 10.1186/s12884-017-1223-x

23. Liabsuetrakul T, Vittayanont A, Pitanupong J. Clinical applications of anxiety, social support, stressors, and self-esteem measured during pregnancy and postpartum for screening postpartum depression in Thai women. J Obstet Gynaecol Res2007; 33:333-40. [PubMed] [Google Scholar]

24. Sarah Myers, Sarah E. Johns. Male infants and birth complications are associated with increased incidence of postnatal depression. Social Science\& Medicine, 2019; 220: 56 DOI: 10.1016/j.socscimed.2018.10.008

25. Kettunen $\mathrm{P}$ et al, The Connections of Pregnancy-, Delivery-, and Infant-Related Risk Factors and Negative Life Events on Postpartum Depression and Their Role in
First and Recurrent Depression, Depress Res Treat. 2016; 2016: 2514317. doi: 10.1155/2016/2514317

26. Stein A, Craske MG, Lehtonen A, Harvey A, SavageMcGlynn E, Davies B, et al. Maternal cognitions and mother-infant interaction in postnatal depression and geenerallized anxiety disorder. JAbnorm Psychol2012; 121(4): 795-809

27. Ali NS, Mahmud S, Khan A, Ali BS. Impact of postpartum anxiety and depression on child's mental development from two periurban communities of Karachi, Pakistan: a quasi-experimental study. BMC Psychiatry2013; 13(1): 274.

28. Edwards DR, Porter SA, Stein GS. A pilot study of postnatal depression following caesarean section using two retrospective self-rating instruments. J Psychosom Res 1994;38:111-7.

29. Malik FR, Malik BB, Irfan M. Comparison of postnatal depression in women following normal vaginal delivery and caesarean section: A pilot study. J Postgrad Med Inst 2015; 29(1): 34-7. 